\title{
Artículos
}

\section{Razón y pulsión de muerte: violencia política en el pasado reciente de Guatemala ${ }^{1}$}

\author{
Juan Pablo Gómez* y Bradley Hilgert*
}

Recibido: enero de 2014 / Aceptado: marzo de 2014

En este ensayo reflexionamos acerca de la relación entre violencia, política y genocidio en la historia reciente de Guatemala. Para ello estudiamos una muestra de la producción intelectual sobre dichos tópicos. Los revisamos como campos problemáticos a la vez que mostramos cuáles son las apuestas analíticas que las hacen posibles. El pensamiento estudiado en este ensayo tiene en común la afirmación de que la violencia política en Guatemala es producto de unas estructuras racistas arraigadas en la experiencia colonial. Organizamos el texto en base a dos propuestas de trabajo. La primera estudia el pasado de violencia apoyándose en conceptos como biopolítica. Este análisis muestra cómo la supuesta superioridad blanca nos mueve de una racionalidad que se manifiesta en el orden finca a una necropedagogía que culmina en la eliminación de las poblaciones indígenas. La segunda propuesta complementa la anterior integrando la dimensión psicoanalítica. Pasan a primer plano las estructuras psíquicas que operan y producen el lazo social que admite

Instituto de Historia de Nicaragua y Centroamérica, Universidad Centroamericana (IHNCA-UCA) y The Ohio State University. Correo electrónico: juanp.gomez@ihnca.edu.ni

** Departamento de Español y Portugués, The Ohio State University. Correo electrónico: hilgert.7@ osu.edu

1 Estas reflexiones son fruto del seminario Pensamiento Centroamericano, enseñado desde el Consejo Latinoamericano de Ciencias Sociales (CLACSO), y del cual los autores formaron parte del equipo docente. El seminario contó con la participación de más de 30 estudiantes de distintos países de Latinoamérica. Agradecemos a Ileana Rodríguez, profesora principal del seminario, por su motivación y seguimiento atento de nuestro trabajo; al Instituto de Historia de Nicaragua y Centroamérica (IHNCA-UCA), centro miembro de CLACSO del cual surgió la iniciativa del curso, y a los y las estudiantes del seminario, cuyo interés, aportes, dudas, inquietudes e incluso sensibilidad, motivaron estas reflexiones. 
la experiencia límite del genocidio. La conclusión es que el Estado guatemalteco, tanto como la estructura de poder dominante, ha sido racista, perverso, criminal y psicótico.

Palabras clave: violencia política / racismo / genocidio / Guatemala

\section{Violencia política, racismo, genocidio: articulaciones claves en la historia reciente de Guatemala}

El propósito de este trabajo es exponer cómo una muestra de pensadores centroamericanos analiza la historia reciente de Guatemala y trata de explicar la excesiva violencia política que caracteriza a esta sociedad. Partimos de la consideración de que el racismo es una de las principales razones que explican la violencia política. En este sentido coincidimos con la definición del racismo que nos brinda Martha Elena Casaús: "un elemento histórico estructural...enraizado en la mente y en los corazones de todos los actores que componen la estructura social, opera en cualquier momento como un detonante en contra de la población maya, que siempre ha sido vista con recelo y temor" (2008, p.18). Tenemos en cuenta dos vertientes analíticas. La primera pone más atención a la dimensión biológica y cultural -entiéndase como cultura ilustrada. Tomemos como ejemplo el análisis que realiza Martha Elena Casaús del pensamiento de redes intelectuales en las primeras décadas del siglo XX. Al respecto ella afirma que la "etiología de este racismo es puramente biológica y racial” (2008, p.42). A primera vista esto puede sugerir una reducción a argumentos biológicos, pero consideramos que la autora lo hace para enfatizar cómo la reflexión en torno a la 'raza indígena' tenía en el cuerpo un lugar central de pensamiento. Tal cosa no deja fuera la dimensión y diferencia cultural. En distintos momentos de su reflexión, Casaús alude a las dimensiones culturales del racismo, pero claro está que la cultura se materializa en seres, prácticas, individuos, cuerpos, físicos, corporeidades que son administradas por 'instituciones nacionales'. En esta vertiente analítica la violencia es fundamentalmente epistémica.

La autora también alude a las políticas económicas y de trabajo forzado que perduraron desde la colonia hasta las primeras décadas del siglo XX. Esto nos permite presentar la segunda vertiente de análisis. Tomemos como ilustración el concepto 'dispositivo raza/trabajo agrícola', de AVANCSO (2012). Uno de sus aportes es ampliar el campo de operatividad del racismo, al transitar de política de exclusión y discriminación, a la producción de sujetos y cuadros económicos deseables $^{2}$. El dispositivo raza-trabajo agrícola es una máquina de producción de

\footnotetext{
2 La noción de cuadros deseables viene de lo que los autores definen como "cuadro de riqueza", un término modificado del "cuadros vivos" de Foucault. Para Guatemala, el cuadro de riqueza es producto de una mirada política que define cuatro fuentes de riqueza: 1) tierras fértiles; 2) buen clima; 3) abundancia de agua; y 4) no escasez de "brazos". Es sobre esta última que el dispositivo razatrabajo funciona para producir sujetos-brazos a través de la racialización del trabajo. En palabras de los autores, copiadas de su artículo: "el reto para el pensamiento político fue la imposición de un orden en que cada uno de los elementos constitutivos del cuadro ocupara un lugar y función determinada: desde elementos naturales como la tierra, el clima y el agua, hasta los elementos humanos fueron objeto del pensamiento político y quedaron susceptibles a las estrategias y proyecciones que éste pudiera ejercer sobre ellos"(AVANCSO, 2012). Ver también Gómez y Palma Murga (2010).
} 
población trabajadora a partir de los legados coloniales racistas. La administración de la 'raza' fue eje fundamental de las políticas agrarias y elemento de viabilidad del proyecto finquero-cafetalero en la segunda mitad del siglo XIX.El resultado es la racialización del trabajo y la reducción de las poblaciones indígenas a 'brazos útiles'. Catalogamos esta racionalidad política como parasitaria, ya que la apropiación y consumo de la vida fue la única manera de dar viabilidad al proyecto de 'progreso'. Aquí la violencia es también epistémica, pero pasa directamente por el cuerpo, produciéndolo, administrándolo y, con el genocidio, eliminándolo.

Pongamos atención un momento a los marcos analíticos de estos trabajos. Tanto Casaús como AVANCSO se apoyan en el concepto de biopolítica. Vale la pena recordar que biopolítica es un concepto elaborado por Michel Foucault para dar cuenta de la manera en que la política ha tomado a su cargo la vida humana y societal. Lo encontramos en su obra a partir de seminarios como Defender la sociedad (2002), en el que empezó a hablar de nociones como biopoder y su estrecha vinculación con las prácticas racistas y el racismo de Estado. También desarrolló este concepto -junto a otros de menor circulación como biohistoria- en sus conclusiones del primer tomo de la Historia de la sexualidad (2006) ${ }^{3}$. Harto conocida es la frase en que habla de la mutación de un poder de quitar la vida a uno de dar vida que se desarrolla en la transición a los Estados modernos europeos. Casaús se apoya en este marco analítico para explicar cómo el Estado guatemalteco utiliza el racismo como tecnología de poder,"con la prerrogativa y el derecho a decidir quién ha de vivir y quién no, ejerciendo el derecho a matar o eliminar al Otro en nombre de la soberanía” (2008, p.16).

Mucha agua ha corrido bajo el río después del trabajo de Foucault. Una de las propuestas más importantes es la de necropolítica y fue elaborada por Aquille Mbembe (2003). Él retoma a Foucault y orienta el poder de vida como poder de muerte. Llevemos esto a Guatemala. El genocidio puede ser visto como el quiebre de la biopolítica parasitaria y su paso a una razón necropolítica. Es el paso de un sistema que administra la vida, a otro que la elimina. AVANCSO explica, por ejemplo, que el orden finca no dejaba morir a sus 'brazos', pero apenas los dejaba vivir. Así resume lo que considera son los 'principios de la civilización moderna'. El genocidio entonces puede ser pensado como un momento excesivo y necesario de esta racionalidad, aunque a primera vista pueda ser considerada una transformación aberrante de la misma. La inquietud al respecto es si el genocidio anula o no el funcionamiento del 'dispositivo raza/trabajo agrícola', al eliminar un elemento fundamental del cuadro de riqueza, como es la población.

Este es uno de los temas que aborda Juan Carlos Mazariegos en su excelente trabajo "La guerra de los nombres: una historia de la rebelión, el genocidio y el ojo del poder soberano en Guatemala” (AVANCSO, 2009). Él se pregunta qué sucedería si los 'brazos' se sublevaran y escaparan al registro escópico de la finca. Para responder esta pregunta, Mazariegos trabaja el testimonio de Gilberto Ramírez, una figura que él plantea como "nombre propio de un relato construido por varios

\footnotetext{
3 El análisis y desarrollo que Michel Foucault realiza en estas dos obras sobre el concepto de biopolítica es mucho más útil para nuestras preocupaciones que las reflexiones realizadas posteriormente en su siguiente seminario, Nacimiento de la biopolítica (2007).
} 
textos: es una narrativa intertextual desplegada por los encuentros y desencuentros de las relaciones entre los Otros y Nosotros" (2009, p.8).

Partiendo de esta narrativa y su propia experiencia personal, Mazariegos propone leer el genocidio como una ruptura temporal que constituye una experiencia excesiva de lo innombrable. Cuando los 'brazos' deciden voltear la mirada al finquero, subvertir el nombre y la identidad, enfrentan el poder del ordenfinca. Este acto pone en crisis al poder soberano y activa una latencia de muerte, un "miedo abyecto a carecer" como lo llaman Gilles Deleuze y Félix Guattari (1985, p.34). Según Mazariegos, el estado de excepción convierte al 'brazo' en cuerpo que no importa, en pura carne, en vida desnuda, para utilizar el término de Giorgio Agamben (2003). El genocidio es, entonces, carnicería. Leamos la descripción que nos ofrece Mazariegos:

diríamos nosotros que, en un estado de excepción, donde el registro escópico y el poder panóptico no son efectivos y las relaciones de poder son suspendidas y sustituidas por la 'gran violencia' (violencia pura), la vida se vive como vida pura (sensibilidad impresiva radical): la vida es vida desnuda, pura carne (AVANCSO, 2009, p.47).

Al emerger como sujetos políticos, las vidas antes producidas para servir al cuadro de riqueza ahora son vidas que no merecen vivir. Esto es, a juicio de Mazariegos, el vínculo rebelión-genocidio-poder soberano, todo posibilitado por el racismo, base de la sociedad guatemalteca.

Hemos visto dos polos violentos del racismo, uno en que opera como fuerza epistémica excluyente y otro en que produce un tipo de sujeto específico, sujeto que en un momento sirve al propósito de la producción de riqueza y en otro el de re-afirmar el poder soberano. Es evidente que nuestra reacción como estudiosos del racismo es la de perplejidad -y de rabia también, ¿no es cierto?- al constatar que la retórica nacional distingue y jerarquiza entre vidas indispensables y prescindibles para su reproducción.

Regresemos a Casaús, quien también responde a la pregunta de Mazariegos y propone que al ser conceptualizados como 'enemigos internos', las poblaciones indígenas se convertían en vidas indignas de ser vividas y prescindibles en aras de conservar el 'orden de la nación'. Esta última es importante porque podemos pensar lo nacional como necro-pedagogía. Siguiendo las formas de concebir el genocidio, planteadas por Mazariegos y Casaús, podemos leer estos actos excesivos como disciplinarios, intentos de enseñar un comportamiento 'adecuado' y 'aceptado'. La enseñanza es que no se debe salir del marco del orden finca. En la medida en que esta pedagogía implicaba la muerte, podemos calificarla como necro-pedagogía, apoyándonos en el concepto de necropolítica de Mbembe antes señalado. La muerte aparece entonces como la condición primaria de lo político, violencia extrema que subyace a la formación del lazo social sustentado en el racismo. Notemos entonces que estamos en una sintonía diferente a la que prescribe el discurso liberal del contrato social, retomada fundamentalmente por la sociología, la ciencia política y la historiografía.

Este aspecto pedagógico también nos lleva a otra dimensión del racismo que es su política de blanqueamiento. La blancura nos sirve de entrada para hablar del 
racismo como política del deseo. Veremos más adelante que el deseo y lo pulsional se vuelven importantes en el análisis de Ileana Rodríguez, pero por ahora recordemos que la invención de lo indígena como inferioridad tuvo en la blancura su horizonte de mejoramiento, de manera que la historia se podía concebir como una trayectoria lineal de camino hacia la materialidad más cercana a lo 'blanco' -la blancura, como la raza, son fantasías, imposibilidades que nos constituyen. Esto es la superioridad española de la cual habla Severo Martínez Peláez en su libro La patria del criollo (1998).

La blancura forma parte fundamental de teorías como la de la colonialidad del poder, de Aníbal Quijano (2000), la superioridad posicional, de Edward Said (1979) y el mito de la inferioridad ontológica, de Paulo Freire (2000). Es una estrategia que ha sido primordial para hacer de lo indígena aquello de lo cual 'todos y todas' nos queremos distanciar y negar, visualizando en la blancura un horizonte estético, político, económico y geográfico que perseguir -aunque ésta, aparentemente, se coloque supuestamente fuera del orden discursivo. A esto se está refiriendo Casaús cuando nos dice que el racismo surge de un imaginario falso de la sociedad en que los ladinos se plantean a

sí mismos como 'blancos por oposición al indígena'; blancos por genética, blancos por cultura, blancos por educación, en suma, blancos por definición (...) aquellos guatemaltecos que se consideraban criollos o ladinos decidieron, al fin, convertirse en 'blancos' y crearon una imagen distorsionada de su identidad étnica, al negarse, una vez más, a construir un proyecto de identidad nacional (2008, p.43).

En sus efectos históricos, la fantasía de la blancura ha obstaculizado construir una historia propia, no solo a indígenas, ladinos y mestizos, sino también a los mismos criollos que se consideran blancos.

No queremos cerrar este acápite sin llamar la atención a la posicionalidad del sujeto ladino en esta trama que estudiamos -asunto fundamental a tratar en la historiografía guatemalteca. Llama la atención que la discusión en torno al racismo ha tendido a mostrarnos que las polaridades en pugna son indígena vs ladino. Esto refuerza esa aparente ausencia de la blancura en los antagonismos de 'lo político'. Nosotros consideramos importante la puesta en marcha de una analítica que se pregunte por la localización de los sujetos de enunciación y los enunciados: ¿quién habla por indígenas y ladinos? ¿es realmente el sujeto ladino quien enuncia?

\section{Genocidio: latencia de muerte perpetua}

Sigamos con el postulado de Casaús que señala al genocidio como la máxima expresión del racismo en Guatemala. Reconozcamos en este postulado su disposición a la historización del pasado reciente del país en vinculación a un pasado más lejano pero presente; un pasado-presente. Así visto, el genocidio no puede ser interpretado como una violencia aislada o específica de una coyuntura política que, en el caso guatemalteco, es el conflicto armado. Por el contrario, es resultado excesivo de prácticas sociales signadas por la violencia, que encuentran 'sentido' en una sociedad en la cual el racismo es eje constitutivo y estructurador. Según Rodolfo 
Cardenal, el pueblo de indios fue la "pieza clave de la estructura colonial" (1996, p.53). Esta práctica implicaba una organización jerárquica y racial de la población que concentró la mayoría de la población colonial en poco espacio, sometiéndola también a condiciones pésimas de vida y trabajo. El pueblo de indios forma base de la estructura colonial y parte de lo que Cardenal llama el terror colonial:

El terror colonial se implantó sobre dos premisas sociales: una población indígena aprisionada en un régimen económico que le cerraba toda posibilidad de superación, y, complemento de la anterior, la sociedad colonial daba a los indígenas únicamente aquellos elementos culturales absolutamente indispensables para llevar adelante la explotación, compensando con el número y la violencia el bajo rendimiento de una masa trabajadora sumida en una enorme inferioridad de recursos materiales e intelectuales (1996, p. 67).

Así, vemos que el racismo fue elemento esencial a la sociedad centroamericana desde sus principios coloniales.

La utilidad del impulso historizador radica también en que nos conduce a preguntarnos cómo ha sido posible la perduración del racismo y, más aún, sus efectos degradantes sobre la vida social. Para entender esto, Casaús se mueve entre los pasados coloniales, la fundación de los Estados-nación en el siglo XIX, el pensamiento de algunos círculos intelectuales de las primeras décadas del XX, hasta llegar al conflicto armado y la ejecución del genocidio. En cada una de estas etapas la autora trata de ir señalando la presencia del racismo y su estrecha vinculación con la violencia de Estado 4 .

Apoyándose en teóricos del holocausto, como Zygmunt Bauman, para Casaús la categoría que provee inteligibilidad a la relación racismo-genocidio es la de modernidad. Esta última alberga las condiciones necesarias para que los genocidios sean una posibilidad latente. La modernidad desarrolló una tecnología de poder a la cual la 'raza' quedó anudada como elemento de sus cálculos gubernamentales.

Este gesto analítico es importante porque, como ya vimos antes, nos confirma que el racismo es mucho más que una estrategia de discriminación cultural. El racismo permite la (re)creación de la sociedad a lo largo de distintos procesos históricos.

\footnotetext{
4 Aquí vale mencionar que Guatemala no es caso aislado o único cuando al ejercicio de la violencia se trata. En la región centroamericana los procesos de formación estatal han implicado altos niveles de violencia sobre la población, particularmente sobre los sectores populares, indígenas y mujeres. Tomemos un ejemplo de El Salvador, país vecino a Guatemala. En la investigación de Patricia Alvarenga (2006) sobre la cultura de la violencia en este país, queda más que claro que el Estado fue mal árbitro de lo social y terminó siendo responsable de la matanza indígena-campesina de 1932. De manera similar, el Estado es, en el estudio de Casaús, el actor principal que configura y ejerce prácticas racistas que eliminan sus poblaciones indígenas. Lo mismo vemos en el texto de Ignacio Ellacuría, "A sus órdenes, mi capital”, en el que describe cómo en 1976 un 'nuevo Estado' empezó a aplicar la ley de la reforma agraria hasta que los sectores oligárquicos del gran capital pararon dicho proyecto, dándonos otro ejemplo de la complicidad del Estado frente los poderes dominantes, la "dictadura del capital privado" que ejerce sus múltiples formas de violencia sobre sus poblaciones (véase Ellacuría, 1995, p. 654). En el estudio de Casaús, el Estado no es solamente un cómplice sino el actor principal que configura y ejerce prácticas racistas que eliminan sus poblaciones indígenas. La centralidad del Estado en el ejercicio de la violencia también tiene implicaciones analíticas que retomaremos más adelante (véanse: "La cultura de la violencia. Campesinos y terratenientes en conflicto" y "La formación del aparato represivo", en Alvarenga, 2006; y Ellacuría, 1995).
} 
Pongamos como ejemplo el desplazamiento del pueblo de indios colonial a la finca cafetalera del último tercio del siglo XIX. En este proceso histórico -clave de la modernidad guatemalteca- la perduración de la 'raza' como criterio de clasificación social sirvió para materializar tales cambios y dar viabilidad a los nuevos escenarios que demandaban los mercados internacionales y sus nuevos ejes de acumulación (AVANCSO, 2012; Tischler, 1998; Gallini, 2009). Una gubernamentalidad en torno a la 'raza', entonces, ha sido condición de posibilidad de sociedad en la historia guatemalteca. ¿Cómo ayuda esto al entendimiento del genocidio y la historia reciente? Ayuda porque lo que se ve es una continuación de lo mismo; raza sigue siendo el eje sobre el cual se construye la sociedad. Lo que cambia es que con el genocidio el racismo no sirve para proveer brazos para activar el cuadro de riqueza, sino para el imperativo de eliminar la población indígena y lograr la perdurabilidad de la sociedad según el imaginario dominante blanco.

Un genocidio como el de la historia reciente guatemalteca es propio de las formaciones nacional-estatales con diseños monoculturales; resultado de pasados coloniales como el que nos ilustra Severo Martínez Peláez en La patria del criollo - ellos mismos productos de políticas de muerte. Casaús y otras estudiosas de la sociedad guatemalteca afirman que la gobernancia colonial es racista. Como ya vimos con Cardenal, dicha gobernancia descansa en la diferenciación étnica. El Estado liberal se plantea como la superación de esta desigualdad pero dicha superación nunca se materializa. Edelberto Torres-Rivas (2011) afirma que lo que emerge después de la independencia de Centro América es un Estado liberal-oligarca, un Estado que acarrea en sí ese germen discriminatorio al que acude como fuente de energía violenta. Es decir, las raíces racistas sembradas en la época colonial persisten en y fortalecen al Estado 'moderno' guatemalteco.

El postulado en torno a la relación directaentre racismo y genocidio nos lleva a considerar que este últimose albergaba entonces como latencia de muerte. No siempre lo nominable y enunciable se convierte en algo fáctico, pero el hecho de que sea latencia lo convierte en algo posible, en horizonte de posibilidad política. Más importante aún es mencionar que la dimensión de latencia opera como legitimadora y limpiadora de responsabilidades políticas y sociales. Se supone que algo latente se materialice en algún momento, y no lo contrario. Así, las responsabilidades de toda una sociedad con lo sucedido pueden obviarse, ¿o no?. Nosotros contestaríamos que no junto con Juan Carlos Mazariegos, quien en su trabajo ya mencionado se pregunta sobre su parte en el genocidio, sobre su responsabilidad. Por eso también nos parecen importantes los trabajos recientes de feministas que abogan por cambios culturales que trabajan para eliminar las latencias de violencia y opresión (Sagot, 2012). La pregunta contraria a ¿cómo fue posible lo ocurrido? es ¿por qué es sorprendente que haya ocurrido?

Como señala Casaús, la manifestación fáctica del racismo en las formaciones estatales descansará en el ordenamiento jurídico-político y en el imaginario del Estado, de las elites y, en buena parte, de la sociedad que ayuda a sostenerlo, a su perduración. Este ordenamiento es en buena medida represivo, pero ésta no es su única naturaleza. Las prácticas racistas también se manifiestan a lo largo de la historia de Guatemala a través de políticas de estímulo al mejoramiento poblacional-racial, el estímulo al blanqueamiento. Estudios recientes, como el realizado por Alejandro 
Flores (2014) en AVANCSO, ponen más atención a esta dimensión de las prácticas racistas y muestran cómo la sexualidad es un campo específico en el cual se produce un fuerte impulso hacia el blanqueamiento. Las políticas del multiculturalismo neoliberal y la aparición de lo que Charles Hale llama el 'indio permitido' es otro buen ejemplo de las dimensiones no estrictamente represivas del racismo (2004).

Importante es preguntarnos si la misma estructura estatal que ha (re)producido el racismo es capaz de construir proyectos no racistas ni monoculturales. Como sabemos, esta es una pregunta en discusión actualmente, no solo en Guatemala, sino en muchos países latinoamericanos. Vale mencionar dos polos experienciales al respecto: por un lado la experiencia zapatista que trató de constituir un proyecto fuera del Estado nacional; su contrapunto serían las experiencias bolivianas y ecuatorianas que han tratado de romper el monoculturalismo desde el Estado (Escobar, 2010). En Centroamérica, la gran mayoría de las luchas indígenas se han dado en los tiempos y ritmos del Estado nacional y en los términos de ‘diálogo' que las políticas culturales neoliberales han impuesto. Desafortunadamente, los proyectos revolucionarios no fueron capaces de integrar una comprensión de raza, etnia o campesinado en sus visiones nacionales -tal como lo demuestran los estudios de Jeffrey Gould y Andrés Pérez Baltodano sobre el caso nicaragüense (1998; 2003).

Antes de finalizar este acápite queremos señalar la importancia de los usos políticos de la religión en la relación racismo-genocidio. Casaús señala que la alianza con el neo-pentecostalismo se basó en la doctrina calvinista que "justifica el exterminio de los 'indios' porque no son sujetos de gracia, porque son idólatras, pecadores y representan la fuerza del mal” (2008, p.32). La autora apunta a una alianza estratégica establecida en torno a un imaginario compartido sobre la nación. Otros estudiosos, como Segundo Montes, han demostrado la incidencia de la religión es las políticas racistas en referencia a bautizos, apadrinamientos y compadrazgos (1979).

\section{Bio, necropolítica vs psicoanálisis y la categoría de Estado criminal psicótico}

En su mayor parte, los autores que hemos mencionado hasta el momento se han preocupado por la maquinaria gubernamental que produce la violencia política. Para complementar esta perspectiva nos parece importante la apuesta analítica que desarrolla Ileana Rodríguez en su artículo "Operación Pájaro: Expediente 27, 1998. Obispo Gerardi: Enemigo del Estado; marcado para ser eliminado” (2012). Su interés se orienta enponer mayor atención a la estructuración de la personalidad psíquica, a las mentalidades, en el estudio del terror político, una decisión que la lleva a optar por apoyarse en el psicoanálisis, específicamente en los conceptos de perversión y abyección, y no en otras alternativas analíticas como biopolítica y necropolítica.

Según nos explica Rodríguez, tanto la bio- como la necro-política se sitúan dentro del liberalismo y describen políticas mediadas por la razón. Lo que más nos interesa en este caso tiene que ver con la manera en que el poder se ha ejercido en las sociedades centroamericanas, y particularmente en Guatemala. Lamentando la desarticulación de la reforma agraria en El Salvador en 1976, Ignacio Ellacuría 
declaraba que "viva queda la sinrazón de unos y la razón de otros" (1995, p.656). Es esta sinrazón que pide que nos movamos hacia el campo psicoanalítico para estudiar la pulsión si queremos entender los Estados centroamericanos capaces de actos de genocidio, como vemos en Guatemala. En las palabras de Rodríguez: "en los Estados criminales [...] y esta es mi propuesta, lo que impera es la sin razón, esto es, la pulsión - el ímpetu, el espasmo, las vísceras" (2012, p.19). Con esta última cita ya vemos su segunda apuesta analítica: la calificación de Estados criminales-psicóticos y no Estados fallidos, ésta última usual en algunas perspectivas de las ciencias sociales.

En parte, Casaús ya había anunciado de forma implícita la necesidad de incluir lo no-racional en el estudio sobre la historia reciente de Guatemala. Por eso pone énfasis especial en el aspecto del miedo. En varios de los textos que leímos para el curso sobre Pensamiento Centroamericano se articulaba un tipo de 'miedo criollo', el temor de perder el control y de que se interrumpa el sistema y status quo actual. Podemos leer este miedo como una manifestación del deseo abyecto ante la posibilidad de carencia, como señalamos antes. Casáus nos explica que este miedo tiene un momento culminante en los años 80 cuando la clase oligárquica del país se enfrenta con la posibilidad de perder su poder hegemónico: "en otras palabras, la crisis de dominación oligárquica tocó fondo y, por primera vez existió un temor fundado, de cara a los acontecimientos de Nicaragua y de El Salvador de verse desplazados del poder. Frente a todo ello se reactivaron todos los prejuicios y estereotipos del pasado que seguían vigentes en la mente y en el imaginario" (2008, p.46).El temor que está explicando Casaús es algo que se siente en las entrañas; no es algo que pertenece a nuestras facultades 'racionales'. El miedo blanco es un fantasma y es correlativo al terror impuesto sobre los cuerpos indígenas del que hablaba Cardenal y que citamos arriba. Esto sirve para evidenciar la necesidad de ir más allá de las explicaciones del genocidio como un tipo de racionalidad, y en este sentido vemos necesario el aporte de Ileana Rodríguez y la inclusión de la perspectiva psicoanalítica.

La decisión de optar por la estructuración de la personalidad, un énfasis puesto en las mentalidades, en este caso perversas y/o abyectas, le permite a la autora poner en primer plano una dimensión de la realidad sobre la que Martín-Baró también hacía alusión para el caso salvadoreño: la dimensión psicosocial y la manera en que ésta constituye y forma lazo social. En su texto "La violencia política y la guerra como causas del trauma psicosocial de El Salvador" (1988), Martín-Baró se preocupa por la forma en que la prolongación de la guerra civil produce una destrucción psicosocial caracterizada por la polarización social, la mentira institucionalizada y la mente militarizada, todos ejes que estructuran la realidad del país y resultan en un lazo social deshumanizado.En la misma línea pero estudiando el caso guatemalteco, Rodríguez demuestra que las estructuras psíquicas son perversas y por ende el lazo social será de la misma naturaleza. Para entender esto, tenemos que definir la perversión. La perversión es la quiebra de la norma, la transgresión de la ley, el abandono completo a la jouissance (placer, goce transgresor). Si la estructura psíquica es perversa entonces

5 Entre esta bibliografía destacan: Severo Martínez Peláez (1998); Gustavo Palma Murga (2007, 2012); PatriciaAlvarenga (2006); Ignacio Martín Baró (1988); y Juan Carlos Mazariegos (AVANCSO, 2009). Para ver una descripción completa de la bibliografía del curso, se puede visitar: http://www.clacso.org.ar/ area_academica/2b3.php 
el lazo social se construye sobre la continua disrupción o transgresión de la ley. El placer, en tal caso, no se encuentra en la mantención del lazo social, sino en su constante transgresión.

Lo que permite a Rodríguez esta apuesta es dimensionar que, si bien estamos claros de las políticas racionales y calculadas que llevaron a la planificación del terrorismo de Estado -la biopolítica y la necropedagogía que hemos desarrollado arriba- quizás no lo estamos tanto del placer y el nivel de perversión que demostraron en el terreno los 'perpetradores del genocidio', como les llama Manolo Vela Castañeda (2013) y que tan bien retrata Horacio Castellanos Moya en su novelaInsensatez(2004). Si el soldado del ejército -en gran porcentaje indígena, como señala Vela- fue enviado a eliminar al llamado 'enemigo interno' -entiéndase guerrilla o población civil- por el Plan Sofía y semejantes, ¿por qué mató de esa manera? ¿por qué se ensañaron así con los cuerpos? ¿Por qué ese placer en la muerte?:Por qué matar de una manera 'indescriptible' o casi 'inenarrable' como reclamaba Juan Carlos Mazariegos en su trabajo? ¿Por qué matar al obispo Juan José Gerardi, sobre todo cuando su muerte, a raíz del Guatemala nunca más, significaba exacta y fehacientemente matar nuevamente a todos los muertos que el informe documentaba? (Oficina de Derechos Humanos del arzobispado de Guatemala [ODAHG], 1998). Estas son preguntas cuyas respuestas -es la apuesta de la autoradeben ser buscadas en el terreno de los campos de conocimiento que estudian la psiquis - una psiquis directamente relacionada a los procesos de colonización y dominancia colonial.

El interés por la estructuración de la psiquis de aquellos sujetos que han ejercido la violencia y el terrorismo de Estado no resta legitimidad ni desdice los aportes de los estudios ya mencionados, que han puesto en primer plano la dimensión calculada de la violencia de Estado. Ambas aproximaciones son absolutamente complementarias y necesarias para entender la complejidad, los excesos y las particularidades de la historia reciente de Guatemala. Desde nuestra perspectiva, tan importante es descifrar el nivel de cálculo y razonamiento que tuvo que existir para producir terror y muerte, como también lo es dimensionar la irracionalidad que nos transmiten escenas como las que recupera y analiza Ricardo Falla, en las que leemos sobre pelotones de militares que ríen y gozan mientras destazan a niños con un cuchillo, violan a mujeres, queman los cuerpos (2011).

En este sentido también vale la pena poner atención a la creación 'perfecta' de toda una red de informantes y desinformantes para el ejercicio del terrorismo de Estado y, más aún, una serie de procesos de subjetivación que arrastran a los sectores más vulnerables de la sociedad al juego de la perversidad. Tal es el caso de Rubén Chanax en la novela de Francisco Goldman que Rodríguez estudia (Goldman, 2007).Vemos cómo el Estado produce todas estas redes al servicio de la muerte, pero es incapaz de producir redes para asegurar una vida digna. Estamos entonces ante estructurales estatales ligadas a la basurización y destrucción, y desligadas de la producción de vidas dignas. Así mismo, estamos frente a la contradicción del genocidio en cuanto elimina la reproducción de su propio sistema. Por eso se puede decir que impera la sinrazón. La visibilidad de esto es lo que la noción de Estado fallido no saca a luz y la de Estado criminal-perverso-psicótico sí. El bien común deja de ser el objetivo del Estado, no solo porque el Estado ha fracasado sino más 
bien porque el Estado se ha abandonado al placer, a la jouissance que se produce transgrediendo la ley de profundis, como siempre lo ha hecho el colonialismo. Es la pulsión y la inexistencia de un $\mathrm{NO}$ que no gobierna y este aspecto lo vemos solo al movernos del Estado fallido al Estado criminal-perverso-psicótico.

Con estas afirmaciones surge la pregunta, ¿cómo se llegó a tal nivel de perversión? Rodríguez no tiene como propósito definido en este artículo hacer una especie de historización de la perversión o de la abyección como manifestaciones del lazo social. Sin embargo, a lo largo del texto señala algunos acontecimientos históricamente significativos en términos de conexiones históricas que nos permiten dar sentido a lo que sucedió recientemente. La afirmación más contundente al respecto probablemente sea cuando la autora señala que "los Estados criminales tienen sus ficciones fundacionales en la colonización” (2012, p.30). Si bien esto no contesta directamente la pregunta de cómo se llegó a la perversión, sí informa sobre el sentido y continuidad histórica de estos comportamientos. Recordemos que a esto Edelberto Torres-Rivas lo llama la perduración y reproducción de la violencia fundadora colonial (2011, p.215). Lo que podemos extrapolar del texto de Rodríguez es que es posible entender la colonización como un momento en que se produjo un estado permanente de psicosis social y de perversión institucionalizada. Esto porque lo que vemos en los comportamientos de las clases dominantes y elites productivas desde la colonización es la pulsión, una energía libidinal sin freno abocada a la destrucción cultural de los cuerpos sociales constitutivos de las sociedades indoamericanas. La psicología considera estos comportamientos arcaicos, deseos que no pasan por las prohibiciones de Estados de derecho. Acercándonos al horror a través de los conceptos psicoanalíticos vemos que el resultado es la descomposición del tejido social, ya que la represión de las pulsiones es la condición para el lazo social. Sin represión de ciertos deseos, no puede haber lazo social basado en el respeto y la ley.

Al mover la preocupación primaria a la estructuración psíquica del sujeto pueden surgir objeciones. Por ejemplo, pensar que esto borra responsabilidades de instituciones como el Estado y la fuerza militar. Si seguimos muy de cerca a nuestra autora veremos que no es así. Rodríguez define la perversión como el placer y goce que se produce con la transgresión de la ley. El Estado perverso, entonces, quiebra la norma cuando la norma es el Estado de derecho. Es decir, el lazo social que se produce desde la estructura psíquica de perversión no puede corresponderse a un Estado de derecho en el cual impere un sentido de bien común. En este momento podemos considerar que hay una razón de estado criminal, pero es la estructuración psíquica que la produce, misma que es sostenida por la institución de la impunidad lograda por una camarilla de militares guatemaltecos apoyada por las politicas hemisféricas estadounidenses. Es decir, si nos preguntamos por las limitaciones que puede tener un análisis de lo pulsional en los procesos de justicia, debemos tener en claro que no implica una desestimación de la autoría bajo toda conciencia y la consecuente responsabilidad de ello. El hecho de usar el calificativo de psicótico para definir al Estado no implica el deslinde de su responsabilidad social. Es más, esta visión psicoanalítica de la violencia política carga aún más responsabilidad sobre el Estado y sus instituciones. Si la represión es la condición para el lazo social como dijimos arriba, entonces es la ley que debe normar la conducta humana. En su ausencia se 
produce la perversión. Cuando el Estado no pone coto a estas conductas, no dice 'NO' prohibiéndolas, revela no solo su debilidad sino su complicidad estructuradora y estructurante. Cuando el Estado mismo quiebra la ley que estableció para normar las conductas, el Estado es clínicamente perverso. El Estado perverso produce y sostiene el orden finca. Ahora bien, si el Estado, además de transgredir la ley crea su propia noción de derecho, como el Estado de excepción que estudia Mazariegos, lo que estamos viendo es un Estado psicótico. El Estado genocida es psicótico.

Nos encontramos entonces con dos dimensiones de análisis que hasta cierto punto se ven desligadas: la de la estructura psíquica y la de las políticas estatales de muerte; el psicoanálisis y la biopolítica. No creemos que la noción de Estado criminal sirva a la exculpación o desligamiento de responsabilidades. Por el contrario, trata de servir a la clarificación de la naturaleza criminal de los sujetos y estructuras vinculadas a este proyecto de Estado, a este tipo particular de gobernancia. El análisis de la autora no trata de dictaminar niveles de conciencia o inconciencia en quienes realizaron acciones, sino calificar de qué naturaleza es un lazo social que no solo permite sino fomenta excesos como estos. Según Rodríguez, el lenguaje psicoanalítico nos permite entender que estas situaciones límites demandan "un tipo de personalidad centrada en el yo - narcisista tal vez- para la cual lo único que cuenta es la satisfacción personal, su jouissance" (2012, p.21). Y el lazo social que produce dicha personalidad es, como dice la autora, "de la misma índole". Es importante subrayar que no estamos hablando del yo personal sino del yo institucional y que esta institucionalidad es la que produce el tipo de estructura del lazo social. Por supuesto que ayuda conocer que hay un discurso formado históricamente que va produciendo un estado de (a)normalidad -antes llamamos a esto latencia- en torno a la violencia y la impunidad. Por eso, ideas como la colonialidad, la herencia colonial o del pasadopresente son tan llamativas. Todas intentan explicar la racionalidad moderna detrás de la violencia política que abunda en nuestras sociedades. Pero la otra dimensión retoma el cómo se ejecuta; qué tipo de mentalidad social e institucional posibilita tal nivel de violencia. La perspectiva psicoanalítica se preocupa por cómo, a través del tipo de ensañamiento sobre el cuerpo, podemos conocer el nivel de amenaza que pudo haber representado alguien como el obispo Gerardi, por ejemplo. Si al nivel discursivo la biopolítica es capaz de explicar el razonamiento detrás del acto genocida o el asesinato político, al nivel psíquico tenemos que inclinarnos por la perversión y psicosis para entender este tipo de eventos límites. De esta forma, repetimos, la pulsión ayuda al entendimiento de la biopolítica, como seguiremos explicando.

Quizás ayude llevar esta discusión al terreno del femicidio. Bien sabemos que hay una estructura patriarcal que recorre históricamente nuestras sociedades y que contribuye en buena medida a la inferiorización y basurización de las mujeres y lo femenino. Saber esto, conocimiento que coincidiría con la biopolítica, nos puede ayudar a entender los niveles de violencia hacia las mujeres, pero quizá no nos ayude tanto a explicarnosqué media en la particular naturaleza violenta del asesinato de mujeres en Guatemala y otros países de la región. ¿Se puede racionalizar dicha violencia? En los asesinatos de mujeres predomina lo visceral, abrir el cuerpo de formas muy similares y en lugares muy similares; violaciones y penetraciones con múltiples objetos, en fin, hay muchos más detalles sobre los que tenemos conocimiento por los medios de prensa. A interrogar un poco más esta dimensión, 
tanto a nivel de la estructura psíquica que posibilita el acto como de la sociedad que lo permite y colabora, contribuye el psicoanálisis. Lo que vemos otra vez es que la pulsión impera. El femicidio, tanto como el asesinato de Gerardi, son actos que ocurren al abandonarse a la jouissance, cuando la jouissance consiste en transgredir la ley. El deseo, de esta forma, que produce la jouissance es la destrucción y muerte -y por eso es psicótico. En el lenguaje popular esto se conoce como saña, venganza, impunidad, sanguinariedad.

\section{Memoria, cultura, ciudadanía}

Rodríguez, tanto como Casaús, señalan la importancia de una genealogía de la violencia que tome en cuenta la noción de genocidio como exceso. En este sentido, Edelberto Torres-Rivas coincide con ellas al subrayar en su último libro, Revoluciones sin cambios revolucionarios(2011), la herencia colonial como una de las claves para entender el terrorismo de Estado de la segunda mitad del siglo XX. También notamos una semejanza entre su definición del enemigo interno y lo abyecto planteado por Rodríguez. Para Torres-Rivas, una parte de los rasgos terroristas del Estado fue la indefinición del enemigo. El enemigo interno es nacional pero no ciudadano. La construcción del enemigo se daba a tres niveles, 1) el del subversivo, 2) el del sospechoso y 3) el del apolítico pasivo. Torres-Rivas nos dice que "el asunto es que el poder terrorista percibe enemigos en los tres círculos descritos" (2011, p.220) y dicho enemigo es merecedor de castigo y objeto de seguridad nacional. Aunque en primera instancia parece que esta construcción del enemigo es algo que se aplicaba indiscriminadamente, sabemos que debemos incluir raza, género, sexualidad y clase en dicha construcción. Así, las diferencias clasificatorias se convierten en elementos que sirven para otrificar y (re)producir enemigos. Esta basurizaciónes un comportamiento basado en la pulsión. Lo que aporta Rodríguez con este texto es una forma de acercarnos a esta (i)lógica para entenderla desde los aportes del psicoanálisis. Por eso nos es útil el concepto de lo abyecto que viene de Julia Kristeva (1982). Copiamos la descripción de la autora para ponerla a dialogar con y explicar la noción del enemigo indefinible en Torres-Rivas:

Vivir en lo abyecto-perverso es, como bien dice Julia Kristeva, vivir en una permanente revuelta del ser, dirigida contra una amenaza (a veces impalpable y por eso alucinatoria) que emana de un exorbitante interior o exterior (la amenaza, el terror a la crueldad externa) lanzado más allá de lo posible, lo tolerable, lo pensable. Esa amenaza está dentro y no se puede asimilar...Esto transmite el sentir visceral de cómo el perseguido por lo abyecto no tiene un objeto definible que lo enfrenta, sino una nada, una presencia ubicua, como la de Dios, el mal o el ejército. Lo abyecto tiene solo una cualidad del objeto: ser opuesto al Yo (Rodríguez, 2102, p.20).

¿No son obvias las semejanzas entre el enemigo interno (nacional pero no ciudadano) y la noción de lo abyecto? La perversión, como una estructura mental, ayuda a entender cómo un sujeto llega a construir a su otro como enemigo, como 
objeto que merece el castigo, como abyecto que tiene que ser 'destazado' o convertido en 'pedazos de carne humana palpitante'. Y cuando el espacio de la ley es ocupado por el cuerpo perverso del ejército, estas prácticas del mal se convierten en la base de lo social.

La producción del enemigo interno o el sujeto abyecto se conecta con lo que Martín-Baró identificó como la mentira institucionalizada en El Salvador. Dicha mentira funciona a través de la creación de una historia oficial custodiada por un "cordón sanitario" $(1988$, p.73) que funciona como un círculo de silencio que implica el olvido del pasado. Este cordón sanitario criminaliza y considera subversivos los intentos de desenmascarar la historia oficial o expresar en público la realidad, denunciar las violaciones de derechos humanos -es una estrategia paralela a la que causó el asesinato del obispo Gerardi. La intervención pública del Comité Coordinador de Asociaciones Agrícolas, Comerciales, Industriales y Financieras (CACIF) en el juicio por genocidio a Ríos-Montt en el 2013 es una evidencia perfecta del 'cordón sanitario'. Dicho Consejo, junto a todas las cámaras empresariales del país, llamó a la ciudadanía y a la Corte de Constitucionalidad a desconocer la sentencia emitida por la juez Jazmín Barrios. Además,se atribuyó facultades judiciales al afirmar que el tribunal de justicia hizo una "calificación inadecuada de la figura de genocidio"en la sentencia que declaró al expresidente Ríos Montt culpable 6 .

Recientemente los estudiosos de memoria han planteado la memoria como una fuerza que desmiente dicha historia oficial ${ }^{7}$. Este también es el gesto de Ricardo Falla en la introducción a su libro Masacres de la selva(1992), donde articula un impulso ético que responde a su manera de concebir el oficio académico. Para Falla, escribir sobre masacres significa documentar la vida que ha sobrevivido la política de violencia y muerte. Y allí, nos explica Falla, yace la potencialidad del testimonio. Leamos sus palabras:

El testimonio, salido del fondo de su memoria emocionada -'nunca lo olvidaré'-, anuncia una realidad existencialmente positiva para él: estoy vivo. Su testimonio es una buena noticia. Mientras más terrible es la narración de lo que presenció, más maravillosa es la realidad que anuncia: estoy vivo. Este libro asume la finalidad de este y de cientos de testigos que quieren decir al pueblo de Guatemala y a las naciones del mundo: estamos vivos, increiblemente, estamos vivos" (1992, p.ii).

El texto de Rodríguez también apuesta por la perspectiva memorística del pasado reciente de Guatemala y contribuye a esta dimensión con su apertura de la noción de archivo. La tercera apuesta analítica de nuestra autora es la de plantear el texto cultural como archivo que documenta formaciones culturales más allá de la normatividad liberal-constitucional. En el texto cultural podemos responder la pregunta sobre dónde están archivadas las memorias, tanto las del terrorismo de Estado, como las de las ciudadanías que tratan de sobrevivir al mismo. Esto es de

6 Ver Montenegro (2013); vale señalar que éste fue uno de varios comunicados en contra del juicio por genocidio.

7 Véanse: Elizabeth Jelin (2003); Nelly Richard (2010); Ileana Rodríguez y Mónica Szurmuk (2008); y Hugo Vezzetti (2009). 
gran beneficio especialmente en sociedades en las que se ha tratado de borrar toda huella, toda voz que rememore críticamente el pasado y se desvíe de la historia oficial. El texto ya mencionado de Ignacio Martín-Baró nos propone la noción del cuerpo como archivo alterno donde el trauma psicosocial instaurado por el Estado queda registrado. Con Rodríguez, esta idea es complementada, ya que ella explica que el trauma marca al sujeto que recuerda, implicando la necesidad de recordar con y en el cuerpo. Y si el cuerpo se vuelve archivo de memoria, también lo es el texto cultural. El texto cultural es capaz de documentar; el texto cultural puede hablar desde las vísceras, desde la somatización de la experiencia vivida. El texto cultural testimonia, cumple con la función de Falla al guardar la memoria de los vivos, así anunciando que siguen vivos.

Uno de los vivos que dan su testimonio en el texto cultural que estudia Rodríguez es Rubén Chanax, un sujeto que ejemplifica la categoría de ciudadanía abyecta. El uso de esta categoría para entender la posicionalidad de Chanax nos distancia de una historia que puede ser contada como la relación de los buenos conlos malos. Como lo dice Rodríguez, Chanax es a la vez la historia del traidor y del héroe tal como la concibe Jorge Luis Borges en su cuento del mismo nombre. Consideremos su historia: Chanax nació en el altiplano y tuvo una niñez difícil antes de ser reclutado por el ejército y entrenado para realizar trabajos criminales para-estatales. Los hechos no son claros, pero podemos suponer que colaboró en el asesinato del obispo Gerardi antes de decidir testificar contra los militares que ordenaron la muerte del obispo. Chanax ocupa el lugar de la duda sobre quién mató al obispo, duda fundamental para entender los procesos de enjuiciamiento de los militares implicados contra los cuales testifica Chanax. Así, Chanax primero sigue las órdenes de los militares y después aparentemente se les voltea y testifica contra ellos. Entonces la pregunta siguiente es qué implicaciones puede tener esta vuelta de la subjetividad en procesos de justicia y determinación de responsabilidades y, sobre todo, en el proceso de reconstitución del lazo social democrático. Vital para la instauración democrática es la posibilidad de revertir el estado de cosas que en el texto de Goldman se encuentra en la figura de Chanax. Como ya hemos dicho, Chanax es un excelente ejemplo de cómo un Estado criminal produce sujetos. Nos hemos preguntado cómo fue posible que todo esto pasara y quizás Chanax es una respuesta excepcional a tal interrogante. Sin embargo, hasta cierto punto él logra mover el ajedrez. Chanax es un sujeto múltiplemente subalternizado, pero trasciende la posición de víctima del subalterno. Como nos dice Rodríguez: "El subalterno hace acto de presencia como colaborador, una sujetividad alterna y diferente de la del oprimido-victimado, una agencialidad y ejercicio del libre albedrío, un arriesgarse que muestra actos de voluntad propia y si consideramos el lado que coadyuva a la 'verdad' y la 'justicia', una ética” (2012, p.27).

También podemos leer los esfuerzos de los abogados de la Oficina de Derechos Humanos del Arzobispado de Guatemala (ODHAG), los 'intocables', como una potencia crítica. El equipo que investigaba el caso de Gerardi definía estos momentos como 'los mejores y más importantes de su vida', 'como una experiencia transformadora.' Su convicción al tomar conscientemente la posición del abyecto y defenderlo es lo que les permite sustraerse de lo abyecto, una tarea que es "un milagro, una transcendencia” (2012, p.20). ¿Podemos encontrar en la posición del abyecto una 
forma de romper con la herencia colonial de la perversión que tanto caracteriza los poderes dominantes? ¿Puede una subjetividad como la de Chanax anudar otro tipo de lazo social? Si para responder consideramos la inclusión de los sectores populares -las subalternidades múltiplemente articuladas que Chanax representa- a las redes del narcotráfico y el crimen organizado transnacional, la respuesta sería negativa. Todavía nos sigue retumbando en el oído aquel aviso de incendio que hizo MartínBaró más o menos un año antes de ser víctima del mismo terror que denunciaba, aviso que afirmaba que la realidad de la guerra era insostenible para la sociedad. Queda por cumplir la tarea de movernos hacia el lado subalterno que construye una ética, como nos plantea Rodríguez. Y para poder tomar esta posición y construirla, es necesario entender la violencia política que produce lo subalterno abyecto desde sus racionalidades y desde sus estructuras psíquicas. A esto contribuye grandemente el estudio del pensamiento centroamericano.

\section{Referencias bibliográficas}

Agamben, G. (2003). Homo Sacer. El poder soberano y la nuda vida. Barcelona: Pretextos.

Alvarenga, P. (2006). Cultura y ética de la violencia. El Salvador 1880-1932.San Salvador: Dirección de publicaciones e impresos.

AVANCSO. (2009). Glosas Nuevas sobre la misma guerra. Rebelión campesina, poder pastoral y genocidio en Guatemala. Guatemala: Autor.

AVANCSO. (2012). "Romper las cadenas": orden finca y rebeldia campesina. El proyecto colectivo finca La Florida. Guatemala: Autor.

Cardenal, R. (1996). Manual de historia de Centroamérica. San Salvador: UCA Editores.

Casaús, M. E. (2008). Genocidio: máxima expresión del racismo en Guatemala. Una interpretación histórica y una reflexión. Guatemala: F \& G Editores.

Castellanos Moya, H. (2004). Insensatez. Barcelona: Tusquets.

Deleuze,G. \& Guattari, F. (1985). El antiedipo: capitalismo y esquizofrenia. Barcelona: Pre-textos.

Ellacuría, I. (1995). Veinte años de historia de El Salvador (1969-1989): escritos políticos. San Salvador: UCA Editores.

Escobar, A. (2010). Latin America at a Crossroads. Cultural Studies, (24), 1-65.

Falla, R. (1992). Masacres de la selva. Ixcan, Guatemala (1975-1982). Guatemala: Editorial Universitaria, Universidad de San Carlos de Guatemala.

Falla, R. (2011). Negreaba de zopilotes. Masacre y sobrevivencia. Finca san francisco, Nentón. Guatemala: AVANCSO.

Flores, A. (2014). Tres semióticas de subjetivación: racismo deseante en Guatemala. En: A. Flores, C. Arenas \& J. P. Gómez (coords.). Seguridad y racismo: pensamiento crítico centroamericano. (pp. 11-37). Managua: UCA Publicaciones.

Foucault, M. (2002). Defender la sociedad. México: Fondo de Cultura Económica.

Foucault, M. (2006). Historia de la sexualidad. La voluntad del saber. Buenos Aires: Siglo XXI.

Foucault, M. (2007). Nacimiento de la biopolítica. Curso en el College de France (19781979). Buenos Aires: Fondo de Cultura Económica.

Freire, P. (2000). Pedagogy of the Oppressed.New York: Continuum. 
Gallini, S. (2009). Una historia ambiental del café en Guatemala. La Costa Cuca entre 1830 y 1902. Guatemala: AVANCSO.

Goldman, F. (2007). El arte del asesinato politico. ¿Quién mató al obispo? Barcelona: Anagrama.

Gómez, J. P. \& Palma Murga, G. (2010). ¿Brazos o ciudadanos? La colonialidad de la nación en Guatemala. Boletín de la Asociación para el Fomento de los Estudios Históricos en Centroamérica(AFEHC), (46), s.d.

Gould, Jeffrey (1998). To Die in This Way: Nicaraguan Indian Communities and the Myth of Mestizaje, 1880-1965. Durham, NC: Duke University Press.

Hale, C. (2004). Rethinking Indigenous Politics in the Era of the 'Indio Permitido'. NACLA Report on the Americas, (38), 16-21.

Jelin, E. (2003). State Repression and the Labors of Memory. Minneapolis: University of Minnesota.

Kristeva, J. (1982). Powers of Horror: an essay on abjection. New York: Columbia UP.

Martín-Baró, I. (1988). La violencia política y la guerra como causas del trauma psicosocial de El Salvador. Revista de psicología de El Salvador, (7), 65-84.

Martínez Peláez, S. (1998). La patria del criollo. Ensayo de interpretación de la realidad colonial guatemalteca. México: Fondo de cultura económica.

Mbembe, A. (2003). Necropolitics. Public Culture, (15), 11-40.

Montenegro, Á. (2013, 13 de mayo). El CACIF le pide a la CC la anulación de la condena contra Ríos Montt. El Periódico. Recuperado el 26 de marzo de 2014, de http://www.elperiodico.com.gt/es/20130513/pais/228188.

Montes, S. (1979). El compadrazgo: Una estructura de poder en El Salvador. San Salvador: UCA Editores.

Oficina de Derechos Humanos del arzobispado de Guatemala (ODAHG). (1998). Guatemala: Nunca Más. Informe del Proyecto Interdiocesano de Recuperación de la Memoria Histórica (REMHI). Guatemala: Oficina de Derechos Humanos del arzobispado de Guatemala. Recuperado el 13 de diciembre de 2013 de, http://www.odhag.org.gt/html/Default.htm

Palma Murga, G. (2007). La institucionalización del trabajo en el campo como mecanismo para el control y la regularización de la vida en Guatemala. Aproximación a los imaginarios sobre organización campesina en Guatemala. Ensayos sobre su construcción histórica. Guatemala: AVANCSO.

Palma Murga, G. (2012). La protesta campesina: una larga y constante expresión de lucha por el reconocimiento y la sobrevivencia. Revista Territorios, (7), 69-84. Guatemala: CONGCOOP.

Pérez Baltodano, A. (2003). Entre el estado conquistadory el estado nación: providencialismo, pensamiento politico y estructuras de poder en el desarrollo histórico de Nicaragua. Managua: IHNCA-UCA.

Quijano, A. (2000). Coloniality of Power, Eurocentrism, and Latin America. Nepantla: Views from South, (1), 533-580.

Richard,N. (2010). Crítica de la memoria (1990-2010). Santiago: Ediciones Universidad Diego Portales.

Rodríguez, I. (2012). Operación Pájaro: Expediente 27, 1998. Obispo Gerardi: Enemigo del Estado; marcado para ser eliminado. Revista de Historia, (27), 17-33. 
Rodríguez, I. \& Szurmuk, M. (2008). Memoria y ciudadanía. Santiago: Cuarto Propio. Sagot, M. (2012). ¿Un paso adelante y dos atrás? La tortuosa marcha del movimiento feminista en la era del neointegrismo y del 'fascismo social' en Centroamérica. A. Carioso (coord.). Feminismo y cambio social en América latina y el caribe. (pp. 75-100). Buenos Aires: CLACSO (Colección Grupos de Trabajo).

Said, E. (1979). Orientalism. New York: Vintage.

Tischler Visquerra, S. (1998). Guatemala 1944: Crisis y revolución: ocaso y quiebre de una forma estatal.Guatemala: Universidad de San Carlos de Guatemala, Escuela de Historia, Instituto de Investigaciones Históricas, Antropológicas y Arqueológicas.

Torres-Rivas, E. (2011). Revoluciones sin cambios revolucionarios: Ensayos sobre la crisis en Centroamérica. Guatemala: F\&G Editores.

Vela Castañeda, M. (2013). Perpetradores de genocidio. Aproximaciones históricas y sociológicas desde el caso Guatemala. Revista Nueva sociedad, (246), 159-169.

Vezzetti, H. (2009). Pasado y presente: guerra, dictadura y sociedad en la Argentina. Buenos Aires: Siglo Veintiuno Editores. 